\title{
Identifikasi Bidang Gelincir Zona Rawan Longsor menggunakan Metode Geolistrik Di Ruas Jalan Toraja - Mamasa
}

\author{
Sudarwin Kamur ${ }^{*}$, Samsi Awal dan Ahmad Iskandar
}

${ }^{1}$ Universitas Sembilanbelas November Kolaka,Sulawesi Tenggara,Indonesia

Email koresponden: geo.darwin@yahoo.co.id

Direvisi: 2020-02-05 Diterima: 2020-07-08

(C)2020 Fakultas Geografi UGM dan Ikatan Geograf Indonesia (IGI)

\begin{abstract}
Abstrak Metode geolistrik tahanan jenis merupakan salah satu dari metode geofisika yang dapat mendeteksi aliran listrik di bawah permukaan bumi. Salah satu aplikasi metode geolistrik tahanan jenis adalah dapat mengidentifikasi bidang gelincir pada daerah rawan longsor. Penelitian ini bertujuan untuk mengetahui bidang gelincir pada daerah rawan lonsor di ruas jalan Toraja - Mamasa. Hasil dari pengukuran geolistrik tahanan jenis dipadukan dengan hasil pengeboran di beberapa titik agar tidak terjadi kesalahan dalam proses interpretasi batuan yang diduga sebagai penyebab terjadinya tanah longsor. Informasi tentang perlapisan tanah tersebut digunakan untuk mengetahui batas-batas ketidakstabilan pada lapisan tanah yang dapat menjadi acuan dalam pengembangan wilayah, khususnya ruas jalan Toraja - Mamasa. Dalam penelitian ini diperoleh nilai resistivitas yang berbeda-beda untuk setiap batuan. Variasi resistivitas yang diperoleh dimulai dari $0-978 \Omega \mathrm{m}$. Nilai resistivitas batuan pada bidang gelincir di lokasi penelitian berada pada bidang batas $50-300 \Omega \mathrm{m}$. Batuan penyusunnya berupa batupasir lempung, lava andesit dan basalt.
\end{abstract}

Kata kunci: bi d a ng ge lin cir;t a n a h longs o; geolistrik dan litologi

Abstract The resistivity geoelectric method is one of the geophysical methods that can detect the flow of electricity below the earth's surface. One application of the resistivity geoelectric method is to identify the slip field in landslide prone areas. The research aimed to discover slip area of landslide prone zone at the segment road of Toraja-Mamasa. The results of the geoelectric resistivity measurements are combined with the results of drilling at several points so that there are no errors in the process of rock interpretation which are thought to be the cause of landslides. Information about the soil layers is used to determine the boundaries of instability in the soil layer which can be used as a reference in regional development, especially the Toraja - Mamasa road segment. In this research, it was obtained different resistivity values for each rock. The resistivity variation obtained started from $0-978 \Omega \mathrm{m}$. The rock resistivity value in the slip plane at the research location is in the 50-300 $\Omega \mathrm{m}$ boundary fields. The rocks lithologies are clay sandstones, andesite lava and basalt.

Keywords: slip field, landslide, geo-electric and lithology

\section{PENDAHULUAN}

Sering terjadinya longsor di sepanjang ruas jalan Toraja Mamasa membuat beberapa kecamatan di daerah ini terisolir, diantaranya Kecamatan Bittuang, Masanda, Rano, Mappak, Bonggakaradeng, yang berbatasan langsung dengan Kabupaten Mamasa dan Mamuju, Sulawesi Barat. (Tribunnews.com, 2016). Karena faktor tingginya longsor di sepanjang ruas jalan Toraja - Mamasa membuat jalan di daerah ini memerlukan perlakuan khusus dalam penanganannya. Rahmad et al (2017) faktor yang mempengaruhi terjadinya tanah longsor meliputi curah hujan, jenis batuan, jenis tanah, kemiringan lereng, dan penggunaan lahan. Sebagai upaya pengurangan risiko bencana tanah longsor dan untuk menandai kawasan yang berpotensi longsor di suatu daerah, maka perlu dilakukan pengukuran secara detail dan menyeluruh pada kawasan lereng yang terbentuk dari tanah dan berpotensi longsor. Salah satu indikasi suatu kawasan memiliki potensi longsor adalah adanya bidang gelincir di sepanjang lereng. Bidang gelincir ini terbentuk akibat perbedaan lapisan antara lapisan penutup (tanah bagian atas) dengan lapisan yang berada dibawahnya. Lapisan paling atas sebuah lereng biasanya adalah lapisan tanah yang lolos air sehingga air hujan bisa dengan mudah terinfiltrasi ke dalam lereng. Namun air hujan yang terinfiltrasi atau masuk ke dalam tanah biasanya sering terhambat akibat adanya lapisan tidak tembus air (impermeable) yang menjadi bidang gelincir. Bidang gelincir ini bisa dideteksi dengan menggunakan geolistrik (Muchlis, 2015). Manrulu et al (2017) Metode geolistrik digunakan untuk mengidentifikasi bidang gelincir longsor.

\section{METODE PENELITIAN}

Lokasi Penelitian

Penelitian ini dilaksanakan di Kecamatan Saluputti dan Kecamatan Bittuang Kabupaten Tana Toraja Propinsi 


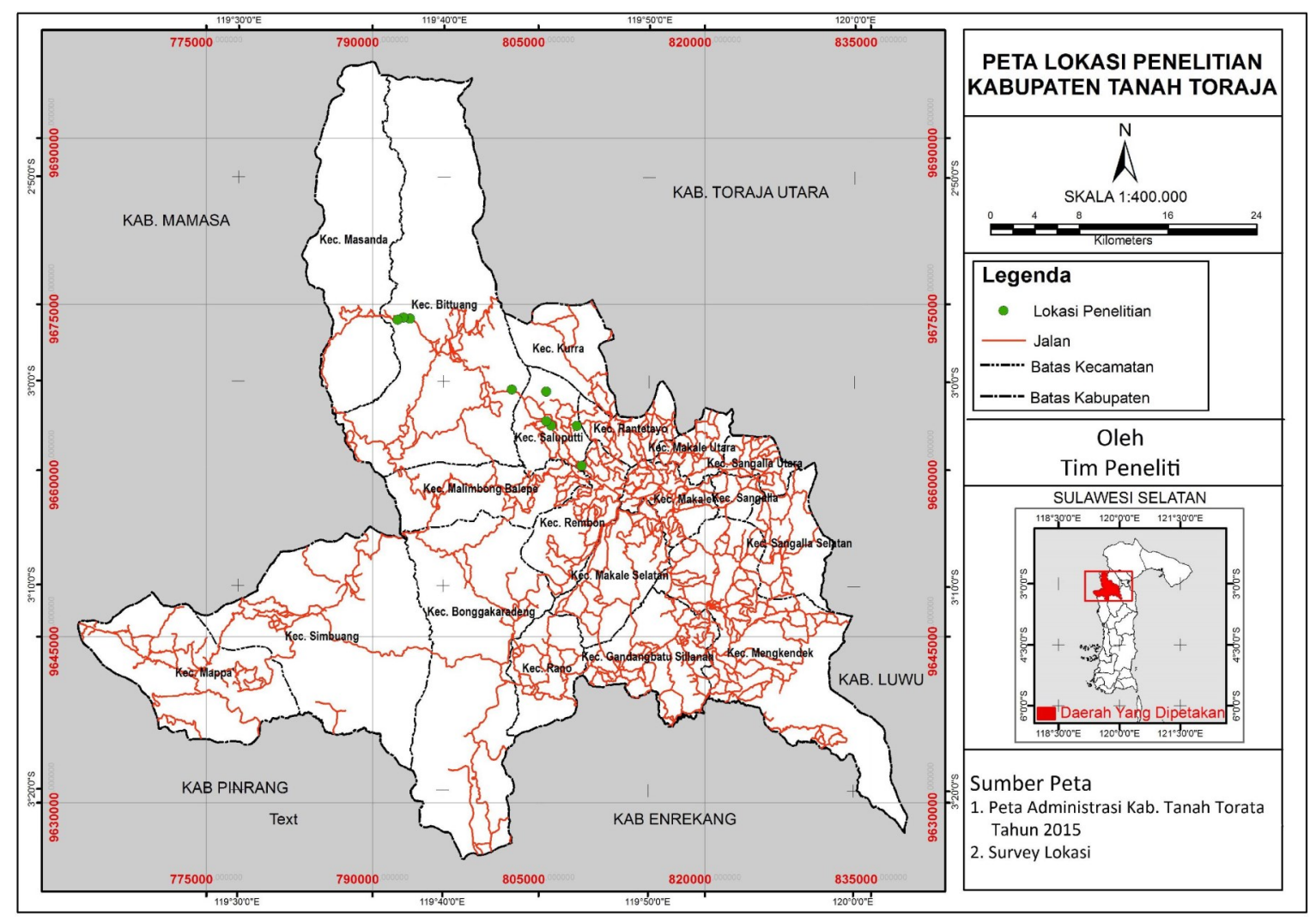

Gambar 1. Peta Lokasi Penelitian

Sulawesi Selatan sebagaimana disajikan pada Gambar 1. Pemilihan lokasi ini didasarkan atas pertimbangan daerah tersebut merupakan wilayah yang sering terjadi longsor.

\section{Metode Penelitian}

Pada penelitian ini menggunakan metode geolistrik tahanan jenis yang dipadukan dengan hasil pengeboran di beberapa titik agar tidak terjadi kesalahan dalam proses interpretasi data yang bertujuan untuk menentukan bidang gelincir yang diduga sebagai penyebab terjadinya tanah longsor. Berdasarkan letak (konfigurasi) elektroda-elektroda arus dan potensialnya, dikenal beberapa jenis metode geolistrik tahanan jenis, antara lain; metode Schlumberger, metode Wenner dan metode Dipole Sounding (Adhi 2007: 1). Informasi tentang struktur dan perlapisan tanah dari hasil geolistrik dan pengeboran digunakan untuk mengetahui batas-batas ketidakstabilan tanah yang dapat menjadi acuan dalam pengembangan wilayah khususnya ruas jalan Toraja Mamasa Propinsi Sulawesi Selatan.

\section{Metode Pengukuran di Lapangan}

Bahan atau materi yang digunakan dalam penelitian ini adalah peta-peta berkaitan dengan daerah penelitian yaitu Peta Rupa Bumi skala 1 : 50.000 lembar Toraja tahun 1999 dan Peta Geologi lembar Majene dan Bagian Barat Palopo skala 1 : 250.000. Peta Rupa Bumi diterbitkan oleh Badan Koordinasi Survei dan Pemetaan Nasional (BAKOSURTANAL). Peta ini digunakan untuk mengetahui dan membatasi lokasi daerah penelitian serta sebagai dasar dalam menentukan lokasi pengambilan data geolistrik dan data-data lain yang tidak terdapat dalam peta tematik lainnya. Sedangkan Peta Geologi diterbitkan oleh Pusat Penelitian dan Pengembangan Geologi Tahun 1982. Peta ini berfungsi menunjukkan jenis dan struktur batuan serta struktur geologi.
Selanjutnya alat yang digunakan dalam penelitian ini terdiri atas alat pengukuran lapangan dan alat pengolahan data. Alat pengukuran di lapangan yang terdiri dari 1 set $S$ Field automatic multichannel, Induce Polarization/IP, Palu geologi, Drill Hydraulic (alat Bor), Kompas dan GPS (Global Positioning System). S-Field automatic multichannel alat yang digunakan untuk mengukur arus dan beda potensial listrik sebagaimana disajikan dalam Gambar 2. Sedangkan untuk meningkatkan kinerja alat S-Field automatic multichannel digunakan Induce Polarization/IP. Palu geologi sebanyak dua buah, digunakan untuk memasang patok dan elektroda ke dalam tanah. Selanjutnya Drill Hydraulic digunakan untuk pengambilan sampel batuan bawah tanah per meter sampai kedalaman yang ditentukan. Terakhir adalah Kompas yang digunakan sebagai penentu arah lintasan pengukuran dan GPS (Global Positioning System) digunakan untuk mengukur kooordinat titik awal dan titik akhir. Sedangkan alat pengolahan data yaitu seperangkat komputer dengan beberapa software pendukung untuk olah data yaitu program excel, notepad, re2DinV, ArcGIS.

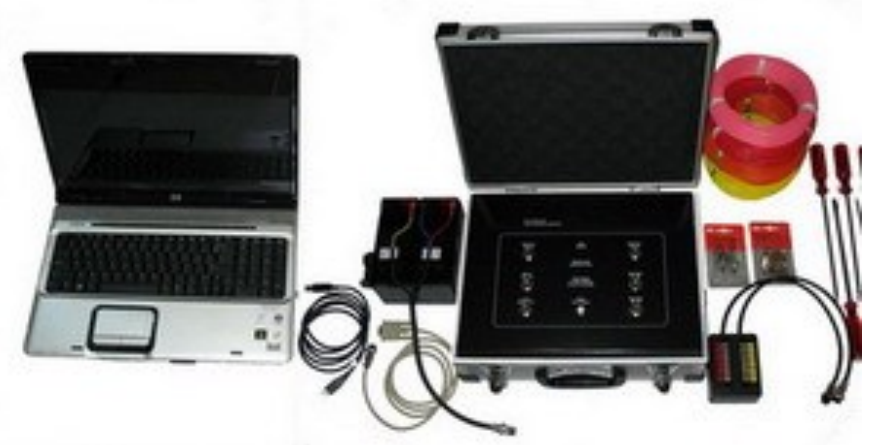

Gambar 2. Alat resistivitas S-Field automatic multichannel 
Tahap Penelitian

Penelitian ini dilaksanakan dengan dua tahap yaitu tahap kerja lapangan dan tahap pasca kerja lapangan. Tahap kerja lapangan terdiri dari tahap persiapan, pengambilan data geolistrik dan pengambilan data geologi. Pada tahapan persiapan, dilakukan free test/calibration terhadap alat yang akan digunakan di lapangan agar berada dalam kondisi siap pakai. Free test/calibration tersebut biasanya dilakukan sehari sebelum pemberangkatan ke lokasi. Selanjutnya mempersiapkan Stacking Chart yang sesuai dengan luas daerah dan kedalaman yang diinginkan pada daerah yang diobservasi sebelumnya. Berikut disajikan contoh susunan model blok dan datum point pada stacking chart pada gambar 3.

Pengambilan data geolistrik dilakukan dengan beberapa prosedur: Pertama, menentukan lokasi pengukuran pada peta lapangan. Beberapa parameter yang perlu diperhatikan pada tahap ini adalah faktor geologi, topografi, dan faktorfaktor lainnya yang berhubungan dengan penelitian. Kedua yaitu menempatkan lokasi titik pengukuran di lapangan. Titik pengukuran yang telah ditentukan pada peta lapangan dicari posisinya secara tepat. Dalam penentuan atau penempatan titik pengukuran diusahakan pada permukaan yang mendatar ataupun miring dan mempunyai lintasan yang lurus. Ketiga adalah mengakuisisi data di lapangan atau pengukuran resistivitas. Pada tahap ini ditentukan posisi yang representatif untuk pengukuran geolistrik dan plot dengan GPS, kemudian mencatat waktu pengukuran dan posisinya. Kemudian menancapkan 16 elektroda pada posisi yang sudah ditentukan. Elektroda ditancapkan dengan cara dipalu ke dalam batu/tanah sampai tingginya bersisa sekitar 5-10 cm. Setiap elektroda diberi jarak sesuai dengan kedalaman yang diinginkan (meter) dengan elektroda yang lain (semakin jauh jarak semakin dalam kemampuan pembacaan alat), yang mana dalam penelitian ini digunakan spasi 7 meter. Selanjutnya memasang kabel yang telah diatur per 7 meter pada setiap elektroda yang telah ditancapkan ke tanah. Kemudian sambungkan ke personal computer (PC) dan alat geolistrik untuk pengambilan data. Alat geolistrik disambungkan juga pada aki sebagai sumber arus listrik dan menjepit setiap kabel pada elektroda yang telah bermuatan arus listrik. Tahap selanjutnya adalah menyambungkan USB pada aki ke computer dan menjalankan software GEORES pada komputer untuk melakukan akuisisi data, serta tahap akhir adalah pengolahan data.

Tahap terakhir yang masuk dalam tahap kerja lapangan adalah pengambilan Data Geologi. Pengambilan data geologi berdasarkan pengamatan hasil pengeboran di lokasi dan pemetaan geologi setempat. Selanjutnya berdasarkan hasil pengamatan dan pemetaan geologi tersebut dianalisis untuk mengetahui formasi batuan di lokasi penelitian.

Setelah menyelesaikan tahap kerja lapangan, maka selanjutnya masuk dalam tahap pasca kerja lapangan. Tahap ini meliputi penentuan nilai faktor geometri $(\mathrm{K})$, tahanan jenis $(\mathrm{R})$, dan resistivitas semu $(\mathrm{Pa})$ serta analisis data untuk pembuatan peta dan penyusunan laporan akhir. Data diolah berdasarkan formula yang telah ditetapkan, sedangkan penampang bawah permukaan dibuat dengan menggunakan Software Res2DinV. Berdasarkan hasil analisis data diperoleh struktur geologi, stragrafi batuan, dan bentuk agihan air tanah lokasi penelitian yang selanjutnya dituangkan dalam bentuk peta. Proses ini sepenuhnya dilakukan dengan menggunakan Software Arcgis. Beberapa hal yang dilakukan dalam tahap ini adalah data yang diperoleh harus diolah lebih dahulu dengan menggunakan microsoft excel sehingga diperoleh nilai faktor geometri, tahanan jenis, resistivitas semu, dalam bentuk file text yang akan dijadikan sebagai input pada proses selanjutnya menggunakan Res2DinV. Adapun langkah-langkah analisis data dengan menggunakan excel yaitu mengaktifkan program excel pada komputer, meng-copy paste hasil data .DAT dari folder penyimpanan data geolistrik di PC ke excel, menganalisa angka-angka yang ditampilakan dan memastikan semua kolom data terisi, serta menyimpan kembali ke bentuk data .DAT atau TEXT. Setelah file data lapangan sudah beradah dalam file text atau .DAT dan mengikuti format data $\operatorname{Res} 2 \operatorname{Din} V$, selanjutnya dilakukan inverse untuk menampilkan gambar penampang bawah permukaan daerah survei. Adapun langkah-langkah proses data dengan menggunakan perangkat Res2dinV disajikan pada Gambar 4.

Interpretasi data resistivitas 2 dimensi (2D) untuk melihat sebaran variasi nilai-nilai resistivitas permukaan lokasi penelitian berdasarkan warna yang diberikan pada penampakan hasil pemrosesan data. Berdasarkan perbedaan

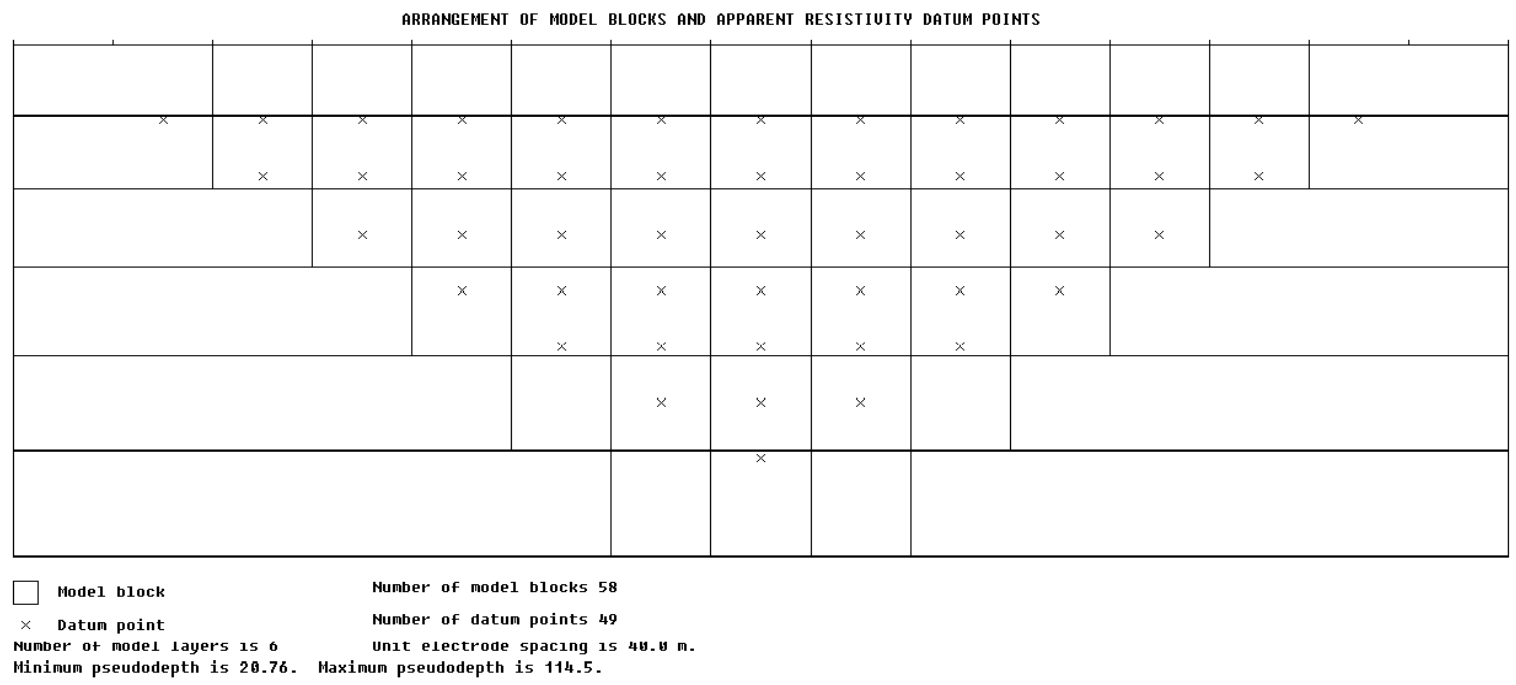

Gambar 3. Contoh Susunan Model Blok Dan Datum Point Pada Stacking Chart 
nilai resistivitas inilah dapat diinterpretasi kedalaman atau datum point dari setiap titik sounding. Interpretasi analisa data ini dilakukan dari beberapa data analisa lapangan dalam penampang geolistrik inversi 2D hasil perhitungan secara matematis yang di lakukan dalam Sofware Res 2 Din $V$ versi 3.54.44 . Hasil interpretasi ini disajikan dalam bentuk penampang tahanan jenis dan interpretasi geolistrik tahanan jenis, serta analisa bidang gelincir dari susunan litologi bawah permukaan di lokasi pengukuran. Hasil inversi 2D di analisa berdasarkan nilai resistivitas dan data hasil pengeboran. Resistivitas batuan dan mineral memperlihatkan nilai yang bervariasi. Pada mineral-mineral logam, nilainya berkisar pada $10^{-5} \Omega \mathrm{m}$, batuan seperti gabbro dengan harga berkisar pada $10^{7} \Omega \mathrm{m}$. Begitu juga pada batuan-batuan lain, dengan komposisi yang bermacammacam akan menghasilkan range resistivitas yang bervariasi pula. Sehingga range resistivitas maksimum yang mungkin adalah dari 1,6 x $10^{-8}$ (perak asli) hingga $10^{16} \Omega m$ (belerang murni) (Telford et al. 1982: 450).

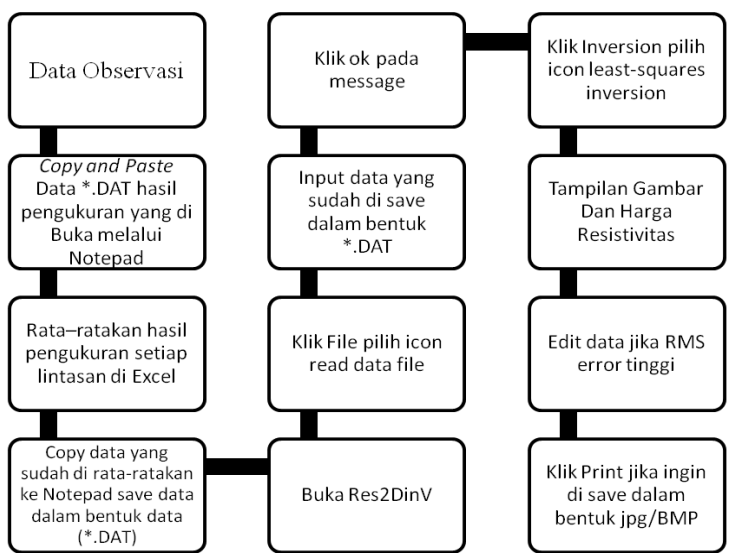

Gambar 4. Skema Langkah Kerja Res2dinV

\section{Drilling}

Setelah memperoleh hasil inversi 2D dianalisa berdasakan nilai resistivitas dan data hasil pengeboran, selanjutnya dilakukan drilling atau pengeboran. Drilling dilakukan untuk membandingkan hasil interpretasi data geolistrik 2D dengan kenyataan di lapangan. Data pengeboran digunakan untuk analisa litologi serta kedalaman batuan di lokasi penelitian.

\section{HASIL DAN PEMBAHASAN}

\section{Hasil Penelitian}

Lokasi 1 (Km 324+800)

Lokasi 1 yang bertempat di Kecamatan Saluputi tepatnya pada KM 324+800 arah Makassar sebagaimana disajikan dalam Gambar 5 dengan Koordinat : Awal (S : $3^{0} 04^{\prime} 07.4^{\prime \prime}$ E : $\left.119^{\circ} 46^{\prime} 44.0^{\prime \prime}\right)$ Akhir (S : $3^{0} 03^{\prime} 56.2^{\prime \prime}$ E1 $\left.19^{\circ} 46^{\prime} 30.4^{\prime \prime}\right)$. Hasil pengeboran dan pengukuran geolistrik di lokasi I disajikan dalam Tabel 1 dan Gambar 6.

\section{Lokasi $2(\mathrm{Km} \mathrm{355+400)}$}

Pengukuran geolistrik pada lokasi 2 dilakukan di Kecamatan Bittuang tepatnya pada $\mathrm{Km} 355+400$ arah Makassar sebagaimana disajikan dalam Gambar 7 dengan Koordinat : awal (S: 2056' 56.3”/ E: 119038'21.6” akhir (S : 2056'59.8”/E : $\left.119^{0} 37^{\prime} 45.3^{\prime \prime}\right)$. Hasil pengeboran dan pengukuran geolistrik di lokasi 2 disajikan dalam Tabel 2 dan Gambar 8.

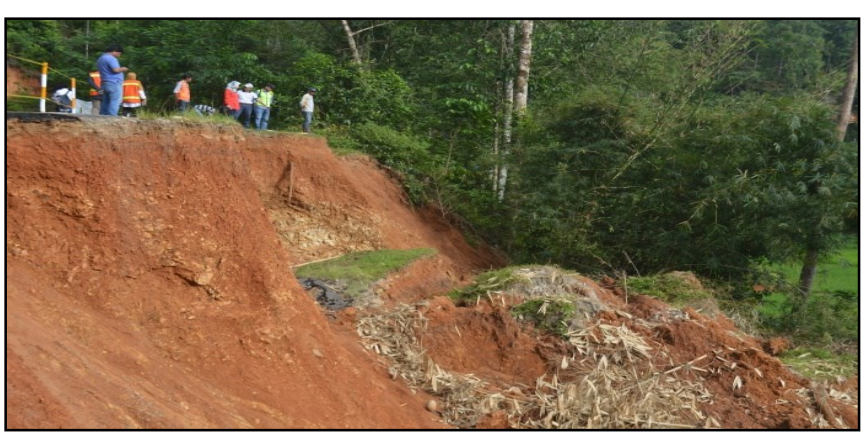

Gambar 5. Longsor di lokasi I

(Koordinat $\mathrm{X}=0808745 \mathrm{Y}=9660595$ )

Tabel 1. Hasil pengeboran lokasi 1

\begin{tabular}{llc}
\hline \multicolumn{1}{c}{$\begin{array}{c}\text { Nama } \\
\text { Pengeboran }\end{array}$} & \multicolumn{1}{c}{ Jenis Batuan } & $\begin{array}{c}\text { Kedalaman } \\
(\mathrm{m})\end{array}$ \\
\hline $\begin{array}{l}\text { Bor Hole } \\
\text { (BH I) }\end{array}$ & $\begin{array}{l}\text { Pasir, Lempung, Kerikil } \\
\text { berwarna coklat }\end{array}$ & $0-11$ \\
$\begin{array}{l}\text { Bor Hole } \\
\text { BH I) }\end{array}$ & $\begin{array}{l}\text { Batulempung berwarna } \\
\text { abu-abu }\end{array}$ & $11-18$ \\
$\begin{array}{l}\text { Bor Hole } \\
\text { BH II) }\end{array}$ & $\begin{array}{l}\text { Pasir campur kerikil } \\
\text { berwarna abu-abu }\end{array}$ & $0-7$ \\
$\begin{array}{l}\text { Bor Hole } \\
\text { (BH II) }\end{array}$ & $\begin{array}{l}\text { Lempung, Pasir campur } \\
\text { kerikil berwarna abu-abu }\end{array}$ & $7-10$ \\
\hline
\end{tabular}

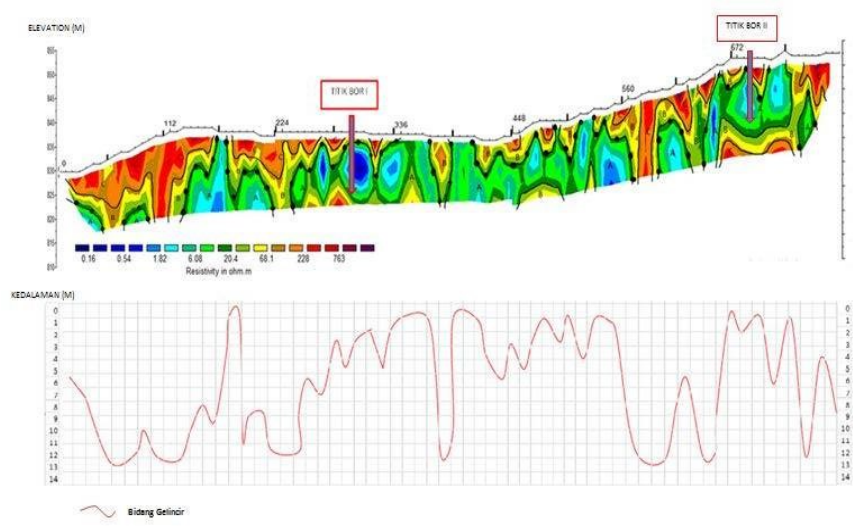

Gambar 6. Hasil pengukuran geolistrik dan identifikasi bidang gelincir di Kecamatan Saluputi

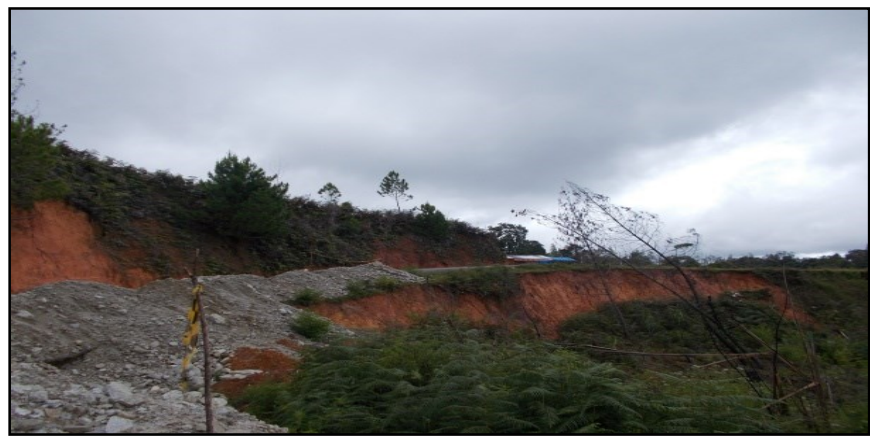

Gambar 7. Longsor di lokasi II (Koordinat X= 0793328 $\mathrm{Y}=9673767)$ 
Tabel 2. hasil pengeboran lokasi 2

\begin{tabular}{|c|c|c|}
\hline $\begin{array}{c}\text { Nama } \\
\text { Pengeboran }\end{array}$ & Jenis Batuan & $\begin{array}{l}\text { Kedalaman } \\
(\mathrm{m})\end{array}$ \\
\hline $\begin{array}{l}\text { Bor Hole } \\
\text { (BH III) }\end{array}$ & Lempung berwarna coklat & $0-5$ \\
\hline $\begin{array}{l}\text { Bor Hole } \\
\text { (BH III) }\end{array}$ & $\begin{array}{l}\text { Lempung, pasir campur } \\
\text { kerikil berwarna kuning ke- } \\
\text { coklatan }\end{array}$ & $5-12$ \\
\hline $\begin{array}{l}\text { Bor Hole } \\
\text { (BH III) }\end{array}$ & Batupasir berwarna kehijauan & $12-15$ \\
\hline $\begin{array}{l}\text { Bor Hole } \\
\text { (BH III) }\end{array}$ & $\begin{array}{l}\text { Lempung campur kerikil } \\
\text { berwarna kuning kecoklatan }\end{array}$ & $15-20$ \\
\hline $\begin{array}{l}\text { Bor Hole } \\
\text { (BH IV) }\end{array}$ & $\begin{array}{l}\text { Lempung berwarna coklat } \\
\text { kemerahan }\end{array}$ & $0-4$ \\
\hline $\begin{array}{l}\text { Bor Hole } \\
\text { (BH IV) }\end{array}$ & $\begin{array}{l}\text { Pasir campur kerikil berwarna } \\
\text { kuning kecoklatan }\end{array}$ & $4-13$ \\
\hline $\begin{array}{l}\text { Bor Hole } \\
\text { (BH IV) }\end{array}$ & $\begin{array}{l}\text { Lempung campur kerikil } \\
\text { berwarna kuning kecoklatan }\end{array}$ & $13-22$ \\
\hline
\end{tabular}

Sumber : Data Pengeboran Lokasi 2

\section{Pembahasan}

Berdasarkan hasil pengolahan data geolistrik menggunakan sofware excel dan Res2Din $V$ di kedua lokasi penelitian Kecamatan Saluputi dan Kecamatan Bittuang diperoleh kedalaman bidang gelincir yang bervariasi. Kedalaman bidang gelincir bervariasi disebabkan oleh pelapukan batuan di daerah setempat. Melkianus et al (2020) Pelapukan batuan tersebut dapat terjadi karena berbagai macam faktor seperti; waktu, jenis dan struktur batuan, topografi, organisme, iklim dan cuaca, serta keadaan vegetasi .Proses pelapukan batuan memiliki pengaruh yang signifikan dalam penentuan bidang gelincir. Proses ini akan mengakibatkan perubahan fisik, mekanik dan kimia batuan pada zona longsoran (Permanajati, 2019). Batuan dan mineral yang mengalami pelapukan menghasilkan partikel dengan berbagai macam ukuran, yaitu batu, kerikil, pasir, lempung, dan tanah liat. Yang tergolong material tanah adalah partikel yang mempunyai diameter lebih kecil dari $2 \mathrm{~mm}$, atau lebih kecil dari kerikil. Tekstur tanah merupakan perbandingan relatif dari berbagai golongan besar partikel tanah dalam suatu massa tanah, terutama perbandingan antara fraksifraksi liat, lempung dan pasir (Ristianto 2007: 16). Rahma et al (2018) Nilai resitivitas batuan/material tidak selalu sama. Nilai resitivitas masing - masing tiap batuan yang sama belum tentu memiliki nilai resitivitas yang sama, dan sebaliknya nilai resitivitas yang sama dapat dimiliki oleh batuan yang berbeda, hal ini bisa dipengaruhi oleh keterdapatan air pada batuan tersebut. Nilai resitivitas beberapa jenis batuan atau material dapat dilihat pada Tabel 3 dan Tabel 4. Nilai resistivitas bidang gelincir berkisar antara $\pm 232-565$ Ohm.meter (Seniwati, 2018)

Kedalaman bidang gelincir di lokasi 1 (Kecamatan Saluputti) terdapat tiga kelas, yaitu sangat dangkal $(<1,5 \mathrm{~m})$, dangkal (1,5 s.d. $5 \mathrm{~m})$, dalam (5 s.d. $13 \mathrm{~m})$. Kedalaman bidang gelincir pada daerah rawan longsor penting untuk diketahui karena dapat mengetahui seberapa besar resiko longsor yang terjadi. Semakin dalam bidang gelincir, tingkat bahaya longsor akan semakin besar. Sebaliknya, semakin dangkal bidang gelincir, tingkat bahaya longsor semakin kecil (Zakaria, 2011). Dari hasil pengolahan data geolistrik yang dikorelasikan dengan hasil bor pada lokasi 1 (Kecamatan Saluputti) resiko untuk terjadinya longsor paling besar terdapat pada bentangan pengukuran $56 \mathrm{~m}, 112$ m, $224 \mathrm{~m}, 392 \mathrm{~m}, 616 \mathrm{~m}, 667 \mathrm{~m}$, dan pada bentangan $756 \mathrm{~m}$ dengan kedalaman rata-rata mencapai $13 \mathrm{~m}$. Sementara tingkat bahaya longsor yang semakin kecil terdapat pada bentangan pengukuran $203 \mathrm{~m}, 364 \mathrm{~m}, 420 \mathrm{~m}, 504 \mathrm{~m}, 532 \mathrm{~m}$, $560 \mathrm{~m}, 672,700$, dan pada bentangan pengukuran $735 \mathrm{~m}$
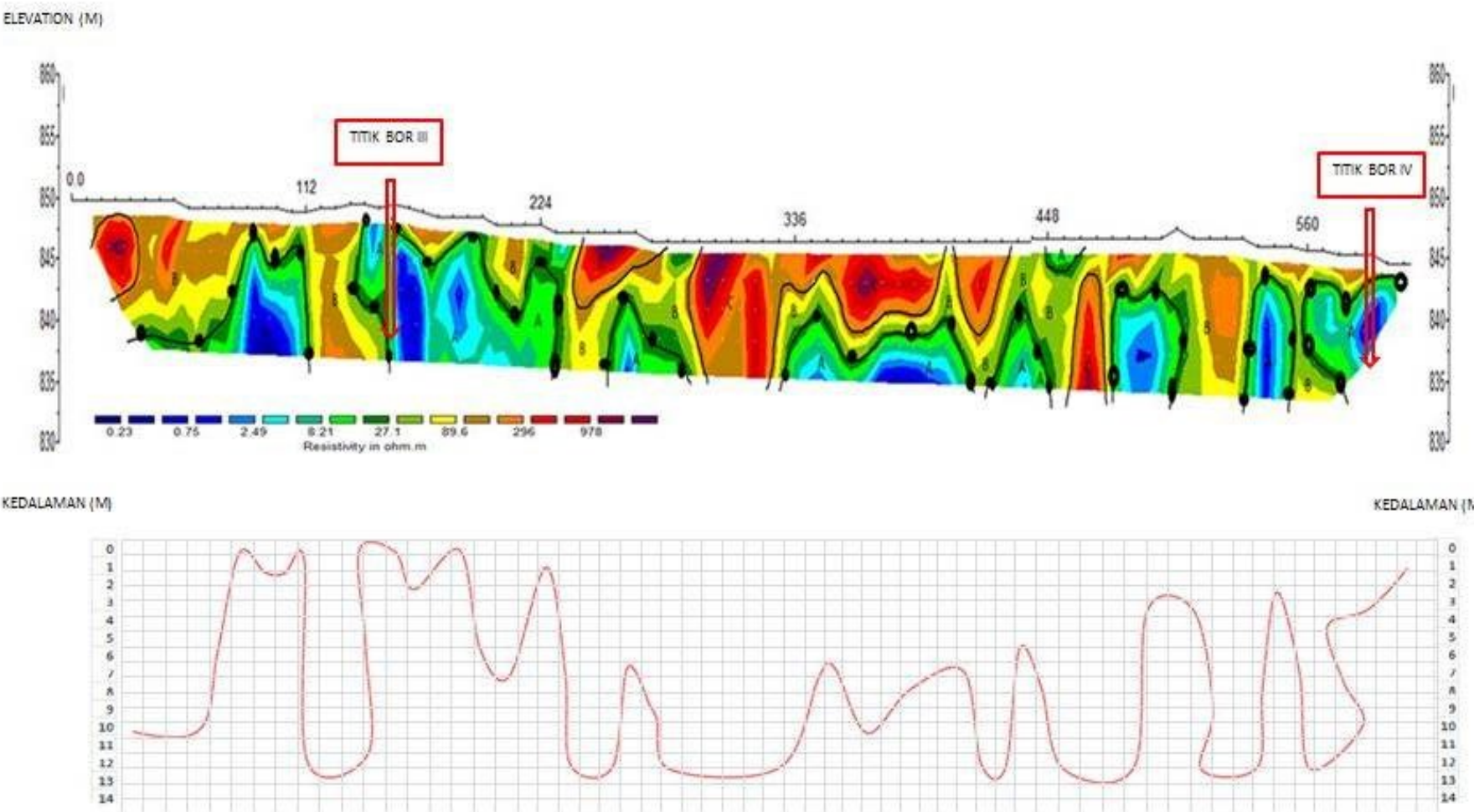

Gambar 8. Hasil pengukuran geolistrik dan identifikasi bidang gelincir di Kecamatan Bittuang 
Tabel 3. Nilai resitivitas Batuan (Rahma et al, 2018)

\begin{tabular}{lc}
\hline Jenis batuan/material & Resistivitas (Ohm.m) \\
\hline Air permukaan & $80-200$ \\
Air tanah & $30-100$ \\
Air sumber & $50-100$ \\
Pasir dan kerikil & $100-1000$ \\
Pasir dan kerikil mengandung & $50-500$ \\
air tawar & \\
Pasir dan kerikil mengandung & $0,5-5$ \\
air asin & $20-200$ \\
Batu lumpur & $2-20$ \\
Lempung & $300-10000$ \\
Batu gamping & $50-300$ \\
Batu pasir lempung & $0,5-5$ \\
Tufa gunung api & $300-10000$ \\
Lava & $0,5-5$ \\
Serpih mengandung granit & $300-3000$ \\
Serpih & $1000-10000$ \\
Granit &
\end{tabular}

Tabel 4. Resistivitas batuan beku dan metamorph (Telford et al. 1982)

\begin{tabular}{|c|c|}
\hline Batuan & $\operatorname{Resistivitas}(\Omega \mathrm{m})$ \\
\hline Granit & $3 \times 10^{2}-10^{6}$ \\
\hline Granite porphyry & $4.5 \times 10^{3}$ (basah) $-1.3 \times 10^{6}$ (kering) \\
\hline Feldspar porphyry & $4 \times 10^{3}$ (basah) \\
\hline Albite & $3 \times 10^{2}$ (basah) $-3.3 \times 10^{3}$ (kering) \\
\hline Syenite & $10^{2}-10^{6}$ \\
\hline Diorite & $10^{4}-10^{5}$ \\
\hline Diorite porphyry & $1.9 \times 10^{3}$ (basah) $-2.8 \times 10^{4}$ (kering) \\
\hline Porphyrite & $\begin{array}{l}10-5 \times 10^{4} \text { (basah) }-3.3 \times 10^{3} \\
\text { (kering) }\end{array}$ \\
\hline $\begin{array}{l}\text { Carbonatized } \\
\text { porphyry }\end{array}$ & $2.5 \times 10^{3}$ (basah) $-6 \times 10^{4}$ (kering) \\
\hline Quartz porphyry & $3 \times 10^{2}-3 \times 10^{5}$ \\
\hline Quartz Diorite & $\begin{array}{l}2 \times 10^{4}-2 \times 10^{6} \text { (basah) }-1.8 \times 10^{5} \\
\text { (kering) }\end{array}$ \\
\hline Porphyry (various) & $60 \times 10^{4}$ \\
\hline Dacite & $2 \times 10^{4}$ (basah) \\
\hline Andesite & $4.5 \times 10^{4}($ basah $)-1.7 \times 10^{2}$ (kering) \\
\hline Diabase porphyry & $10^{3}$ (basah) $-1.7 \times 10^{5}$ (kering) \\
\hline Diabase (various) & $20-5 \times 10^{7}$ \\
\hline Lavas & $10^{2}-5 \times 10^{4}$ \\
\hline Gabbro & $10^{3}-10^{6}$ \\
\hline Basalt & $10-1.3 \times 10^{7}$ (kering) \\
\hline Olivine norite & $10^{3}-6 \times 10^{4}$ (basah) \\
\hline
\end{tabular}

dengan kedalaman di bawah 1,5 m. Lapisan ini tersusun atas batuan lempung dengan nilai resitivitas 0-20 Ohm.meter dan lapisan pasir dan kerikil yang mengandung air tawar dengan nilai resitivity 50-500 Ohm.meter yang diberi kode A. Lapisan ini terdapat di sepanjang lintasan pengukuran. Lapisan ini juga berfungsi sebagai akuifer yang mengandung air permukaan yang turut mempengaruhi gerakan tanah atau longsor terutama pada musim penghujan. Lapisan dengan nilai 50-300 Ohm.meter atau yang berkode (B), merupakan lapisan batupasir lempung yang merupakan bidang batas antara lapisan lunak dan lapisan keras. Bidang batas pada kedua lapisan ini merupakan bidang gelincir pada lokasi 1 (Kecamatan Saluputti). Sementara lapisan dengan nilai lebih dari 300-763 Ohm.meter merupakan lapisan batuan keras yang lebih kompak yang terdiri atas batuan lava andesit dan basalt yang di beri kode (C). Berdasarkan Peta Geologi Regional Skala 1 : 250.000 lembar Majene (2013) dan lembar Palopo Bagian Barat (2013) yang dipublikasikan oleh Pusat Penelitian dan Pengembangan Geologi (1998) jenis batuan di Kabupaten Tana Toraja terdiri atas batuan gunung api, batuan sedimen, batuan metamorfik dan batuan beku. Berdasarkan ciri litologinya batuan penyusun daerah penelitian berupa lava andesit, basalt dan latit kuarsa.

Sementara di lokasi 2 kedalaman bidang gelincir pada lokasi ini bervariasi. Di lokasi ini juga terdapat tiga kelas kedalaman bidang gelincir, yaitu sangat dangkal $(<1,5 \mathrm{~m})$, dangkal (1,5 s.d. $5 \mathrm{~m})$, dalam (5 s.d. $13 \mathrm{~m})$. Hal ini juga disebabkan oleh pelapukan batuan daerah setempat. Dari hasil pengolahan data geolistrik yang dikorelasikan dengan hasil pengeboran pada lokasi 2 (Kecamatan Bittuang) resiko untuk terjadinya longsor paling besar terdapat pada bentangan pengukuran $56 \mathrm{~m}, 130 \mathrm{~m}, 285 \mathrm{~m}, 392 \mathrm{~m}, 532 \mathrm{~m}$, $588 \mathrm{~m}, 670 \mathrm{~m}$, dan $714 \mathrm{~m}$. Kedalaman bidang gelincir dari $10 \mathrm{~m}$ sampai dengan $13 \mathrm{~m}$. Sebaliknya, resiko untuk terjadinya longsor paling kecil terdapat pada bentangan pengukuran $84 \mathrm{~m}, 112 \mathrm{~m}, 168 \mathrm{~m}, 224 \mathrm{~m}, 275 \mathrm{~m}$, dan $780 \mathrm{~m}$. Kedalaman bidang gelincir pada titik-titik ini $<1,5 \mathrm{~m}$. Lapisan ini tersusun atas batuan lempung dengan nilai resitivitas 0-20 Ohm.meter dan lapisan pasir dan kerikil yang mengandung air tawar dengan nilai resitivity 50-500 Ohm.meter yang diberi kode A. Lapisan dengan kode (B) merupakan lapisan batupasir lempung dengan nilai resitivitas 50-300 Ohm.meter yang menjadi bidang batas antara lapisan yang lunak dengan lapisan keras. Batas antara kedua lapisan ini merupakan bidang gelincir pada lokasi 2 (Kecamatan Bittuang) yang terdeteksi pada kedalaman 0-13 meter sepanjang bentangan pengukuran. Sementara lapisan dengan nilai lebih dari 300-763 Ohm.meter merupakan lapisan batuan keras yang lebih kompak yang terdiri atas batuan lava andesit dan basalt yang di beri kode (C).

Longsor yang terjadi di Kabupaten Tana Toraja khususnya di Kecamatan Saluputti dan Kecamatan Bittuang disebabkan karena adanya pelapukan batuan lava berupa pasir dan lempung pasiran. Lapisan tersebut banyak mengandung air permukaan yang membentuk kantongkantong air yang rawan akan longsor, terutama pada musim hujan. Lapisan-lapisan ini membentuk zona lemah pada penyusun batuan.

\section{KESIMPULAN}

Berdasarkan hasil yang diperoleh dapat disimpulkan bahwa di Kecamatan Saluputti dan Bittuang Kabupaten Tana Toraja Propinsi Sulawesi Selatan lapisan batuan terdiri atas 
lempung,pasir dan kerikil, batupasir lempung, lava, andesit, dan basalt yang merupakan batuan Formasi Tineba dan formasi batuan terobosan . Lapisan batuan ini di lokasi terdeteksi dengan nilai resitivitas 0-978 Ohm.meter. Lapisan ini tersusun atas batuan lempung dengan nilai resitivitas 0-20 Ohm.meter dan lapisan pasir dan kerikil yang mengandung air tawar dengan nilai resitivity 50-500 Ohm.meter yang diberi kode (A). Lapisan ini terdapat di sepanjang lintasan pengukuran. Lapisan ini juga berfungsi sebagai akuifer yang mengandung air permukaan yang turut mempengaruhi gerakan tanah atau longsor terutama pada musim penghujan. Lapisan dengan nilai 50-300 Ohm.meter atau yang berkode (B), merupakan lapisan batupasir lempung sebagai bidang batas antara lapisan lunak dan lapisan keras. Bidang batas pada kedua lapisan ini merupakan bidang gelincir pada lokasi penelitian. Sementara lapisan dengan nilai lebih dari 300-978 Ohm.meter merupakan lapisan batuan keras yang lebih kompak yang terdiri atas batuan lava andesit dan basalt yang di beri kode (C).Lapisan-lapisan ini terdeteksi pada kedalaman 0-13 meter. Diharapkan kepada aparat pemerintah/warga setempat sebelum melakukan pembangunan jalan terlebih dahulu diidentifikasi daerahdaerah yang rawan longsor guna perencanaan pembangunan yang lebih baik agar potensi lonsor di ruas jalan RembonMamasa bisa diminimalisir.

\section{UCAPAN TERIMA KASIH}

Alhamdulillah atas Rahmat Allah SWT penulis bisa menyelesaikan penelitian ini. Penulis mengucapkan terima kasih kepada semua pihak yang telah membantu dalam proses penelitian terutama Camat Bittuang dan Saluputti, Bapak Zulfan Rahimy Hamid (pakar geologi) yang telah banyak meluangkan waktu untuk diskusi terkait geologi daerah Kabupaten Toraja serta menggratiskan pemakaian alat geolistrik dan dan alat bor, Bapak Fredy selaku masyarakat asli Toraja yang selalu menemani penulis ketika dilapangan, Bapak Uca dan Amal selaku dosen Geografi Pascasarjana Universitas Negeri Makassar yang telah membimbing penulis sehingga penelitian ini dapat selesai tepat waktu.

\section{DAFTAR PUSTAKA}

Adhi, M.A. (2007). Modul Praktikum Geolistrik. Semarang: Unnes Manrulu, R dan Nurfalaq (2017). Studi Bidang Gelincir Sebagai Langkah Awal Mitigasi Bencana Longsor. Seminar Nasional. Universitas Cokroaminoto Palopo.

Melkianus, A., dkk (2020). Pengaruh Pelapukan Terhadap Kekuatan Batuan Andesit, Institut Teknologi Adhi Tama Surabaya (ITATS), Prosiding, 2 (1)

Muchlis. 2015. Interpretasi Potensi Massa Longsoran Dengan Metode Geolistrik. Aceh: Unversitas Syiah Kuala Darusalam.

Permanajati,I., Iswahyudi, S., (2019). Zona Pelapukan Sebagai Pengontrol Longsoran di Daerah Jingkang dan Sekitarnya, In University Research Colloquium (pp. 234-239) Purbalingga, Indonesia Universitas 'Aisyiah Surakarta

Peta Geologi lembar Majene dan Bagian Barat Palopo Tahun (1998). 1 : 250.000 .Pusat Penelitian dan Pengembangan Geologi Tahun 1982

Rahmad, R., Suib dan A. Nurman (2018). Aplikasi SIG untuk pemetaan tingkat ancaman longsor di Kecamatan Sibolangit, Kabupaten Deli Serdang, Sumatera Utara, Majalah Geografi Indonesia, 32 (1), 1-13

Rahma, H., dkk (2018). Pendugaan sebaran air tanah menggunakan metode geolistrik resistivitas konfigurasi wenner dan schlumberger di kampus 2 Unversitas Cokroaminoto
Palopo, Jurnal Fisika FLUX, 15 (1)

Ristianto, D. (2007). Skripsi (Penentuan Resistivitas Tanah Pada Zona Labil Dengan Aplikasi Geolistrik Metode Tahanan Jenis Konfigurasi Schlumberger (Studi Kasus di Desa Bambankerep, Kecamatan Ngaliyan, Kota Semarang, Jawa Tengah)). Semarang: Unnes (tidak dipublikasikan).

Seniwati, dkk (2018) Penyelidikan Kedalaman Bidang Gelincir Menggunakan Metode Geolistrik Hambatan Jenis pada ruas jalan Tavaili-Toboli, Kabupaten Donggala, 17 (1)

Telford, W.M., L.P. Geldart, , R.E. Sheriff, dan D.A. Keys. (1982). Applied Geophysic. London : Cambridge University Press.

Tribuntoraja,(2016) . Bencana Longsor di Tana Toraja, 35 Ribu Keluarga Terisolir. Satu Orang Tewas Diakses tanggal 27 Januari 2017 dari https://www.tribunnews.com/ regional/2016/04/19/bencana-longsor-di-tana-toraja-35ribu-keluarga-terisolir-satu-orang-tewas?page=all

Zakaria, Z. (2011). Analisis Kestabilan Lereng Tanah. Jawa Barat: Geo Teknik Universitas Padjajaran 